\title{
Cultural Model of Classroom Instruction for ELT in Bangladesh
}

\author{
Mohammad Emdadul Huda ${ }^{1}$ \\ ${ }^{1}$ Department of English Language and Literature, Jatiya Kabi Kazi Nazrul Islam University, Mymensingh, \\ Bangladesh \\ Correspondence: Associate Professor Mohammad Emdadul Huda, Department of English Language and \\ Literature, Jatiya Kabi Kazi Nazrul Islam University, Trishal, Mymensingh, Bangladesh. E-mail: \\ emdadul.huda@yahoo.com
}

Received: October 20, 2012 Accepted: November 5, 2012 Online Published: January 25, 2013

doi:10.5539/ijel.v3n1p67

URL: http://dx.doi.org/10.5539/ijel.v3n1p67

\begin{abstract}
It is now argued that a very close relationship exists between culture and learning, and that learners can learn better if the way of their learning corresponds to the cultural features of their society. Taking this argument into account, many linguists, teachers and researchers now suggest that language teaching-learning practices in the classroom should be based on learners' culture. They argue that if there is a harmony between the mode of teaching-learning activities in the classroom and the cultural features in the broader community outside the classroom, learners can behave competently in the classroom and can, therefore, learn effectively. The present article has attempted to discuss this relationship between culture and learning in general, and also between culture and language learning in particular, with a view to determining a cultural model of classroom instruction for ELT in Bangladesh.
\end{abstract}

Keywords: culture, learning, relationship, context, socialization, harmony, classroom instruction, CLT, teacher-centred classroom, appropriate methodology, Bangladesh

\section{Introduction}

There was a time when culture was not considered to be an important issue for learning. But from the last part of the last century it has come to be an important issue not only for learning in general, but also for language teaching and learning in particular. Culture is now thought to be closely related to learning, and hence, it is suggested that pedagogical principles for teaching-learning activities should be determined by taking the culture-issue into account. The knowledge of the close relationship between culture and learning has given rise to new thinking about the classroom teaching-learning practices in a particular context. It is now argued that the pedagogical principles for the classroom teaching-learning practices in a particular society or in a particular context have to be harmonious with the cultural issues of that society or that context. If there is any disharmony between the cultural issues of the wider society and the pedagogical principles, the teaching-learning activities are bound to suffer. Therefore, to determine the appropriate mode of classroom teaching-learning practices for ELT in the context of Bangladesh, it is important to take the cultural features of this context into account. Therefore, the present article has dealt with the following questions:

1 . What is the relationship between culture and learning?

2. What are the implications of this relationship for effective classroom instruction?

3. What should be the appropriate mode of classroom instruction for ELT in the context of Bangladesh in accordance with the cultural features of the country?

\section{Relationship between Culture and Learning}

According to sociologists, we live in a society that is cultural in nature. Every society has its own values, norms, ways of life, and systems of education, administration and production. When a child grows up as a member of a society, he or she is socialized by his/her parents, older peers and other adult members of that society, and in that process of socialization he/she acquires the values, norms and beliefs of that society. The values, norms and beliefs which a child acquires through this socialization process as a member of a society ultimately determine his/her perceptions and experiences of the world. It is argued that the values, norms and beliefs as well as the perceptions and experiences which a child acquires in this process are his/her cultural profiles which have a very 
close relationship with learning. This claim about the relationship between culture and learning can be better explained through a discussion about the relationship of culture with our mental process of learning and also with the concepts we develop to interpret this world.

\subsection{Culture and Mental Process}

The sociocultural theory of mind emphasizes the point that culture significantly affects the mental process of thinking or functioning. In his attempt to promote this theory, Vygotsky (1978) argues that there is an inherent dialectical relationship between culture and mind, and that psychological phenomena should be understood only by examining their genesis in a culturally situated activity. He also argues that while dealing with the higher mental processes, our brain works through the use of symbolic artifacts which are culturally constructed to be modified by each generation. That is, higher mental functions such as logical memory, selective attention, reasoning, analysis, meta-cognitive dimension of problem solving and so on which were so far believed to have had their origin in the material substance of the brain or in the spiritual substance of the mind have to be understood as culture-related activities. Vygotsky (1978) does not agree with the cognitive psychologists that mental functions are the result of cognitive predisposition and that they have no relationship with the social and cultural conditions under which we live. He claims that these mental functions are generated in goal-directed mediated activities. It is because of the significant role that the symbolic artifacts play in the functional system of human mind, "the task of psychology, in Vygotsky's view, is to understand how human social and mental activity is organized through culturally constructed artifacts" (Lantolf, 2000).

\subsection{Culture and Concepts}

Culture, as it is argued, also plays a very vital role in developing our various concepts which help us to perceive everything of the world. We develop these concepts through our experiences as members of a society, and then these concepts govern the structures of our perceptions and also every fact of our daily activities including learning. According to Keil (1989, 1 cited in Lantolf 1999, 31), the concepts developed through culture can be thought of as networks of systematic beliefs about how the world is. Shore (1996, 47 cited in Lantolf 1999, 31), following Vygotskyan stance, points out that concepts have their origins in two primary sources, personal mental models and cultural models. About cultural models, he says, they are formed and transformed as a consequence of the endless negotiation among the members of a particular community as they go about the business of living. They are conventionally constructed and shared cognitive resources of a community. About personal mental models, Shore says, though they are formed by individuals as a result of their unique experiences of life activity, they are dialectically interrelated with cultural models. According to Vosniadou (1991, 286), our mental life is a reflection of cultural reality. To understand what goes on inside the head of a man, he says, it is necessary to understand the cultural context where the man operates. Every man, he continues, constructs his mental model out of his socio-cultural realities. Referring to the findings of recent research, he echoes the views of Vygotsky (1978) that we need to recognize the significance of culturally mediated ways of understanding and explaining the world to understand the nature of mental process. According to Vygotsky, we use the symbolic tools or artifacts which are culturally constructed to establish an indirect and mediated relationship between ourselves and the world. In other words, culture should be seen as a mediating device, a filter through which we perceive the world and render it intelligible.

\subsection{Limitations of the Behavioural and Cognitive Theories of Learning}

The claim about the relationship between culture and learning has been strengthened as behavioural and cognitive psychologists fail to explain the complexities of learning process. Behavioural psychologists explain learning as a mechanical process of habit formation in which there is a close relationship between the overt behaviour of learners and the forces in the external environment. Quite oppositely, cognitive psychologists explain it as a mental process which can be better understood by analyzing what goes inside the minds and brains of learners. However, both behavioural and cognitive psychologists try to explain the complexities of learning process by some general formulas, which, they claim, are equally applicable to all the tasks of learning as well as to all people. But, they fail to find a satisfactory answer as to why children can do some tasks in some contexts, but not in others (Donaldson 1978 cited in Vosniadou 1991, 285) or, why people from non-Western cultures can show very good skills at some tasks such as logical inferencing, calculating, memorizing when engaged in problem-solving activities, but not when asked to perform intelligence test (Gladwin 1970 cited in Vosniadou 1991, 285). They also fail to provide a satisfactory answer as to why the people who have difficulty with a particular laboratory task can show sufficient skills to complete it in the context of some culturally meaningful activity (Scribner \& Cole 1973 cited in Vosniadou 1991, 286). A large body of research which was conducted on learning issues during the last two decades has found it impossible to explain the learning issues without culture. 
According to Saljo (1991, 180), both behaviourists and cognitivists take a limited view of learning. Behaviourists limit it by offering a theory of senseless acquisition of behaviours, on the one hand, and cognitivists limit it to the disembodied application of the mythical cognitive process to the world, on the other.

\section{Implications of the Relationship between Culture and Learning for Instructional Process}

Because of the close relationship between culture and learning, many educationists, researchers and experts now argue that an instructional process of learning cannot be successful if we do not base it on the cultural traits of the learners. For the successful occurrence of learning they suggest cultural model of instruction. Arguing for the cultural model of instruction, Pinxten $(1991,220)$ says that if a society-like situation is created in the classroom, learners will feel free from any cultural constraint and behave competently in the classroom. He argues that before starting their formal education, learners acquire a body of fairly rich informal knowledge through their exposure to culture and participation in activities organized in society. This informal knowledge is very important as it serves as a basis for formal learning at school. He, therefore, emphasizes knowing learners' culture because knowledge about it enables us to set up such a situation in the classroom as is similar to the broader society outside the classroom. He argues that if this informal knowledge of learners can be utilized through instructional process, it makes learning easier and more stable for learners, and enables them to acquire the formal education in a meaningful way with intrinsic pleasure of understanding. Like Pinxten, many other experts and researchers also believe that there should be a similarity between what goes inside the classroom and the cultural pattern outside the classroom. They argue that the mode of instruction in the classroom always involves social interaction and artifacts in the form of educational aids and materials which bear cultural values. Larger socio-cultural contexts affect what goes on in the classroom both institutionally and formally. According to Saljo (1991), what occurs in the microenvironment of the setting of learning is affected by larger contexts. His view signifies that the interactions of the learners with the people and artifacts outside the classroom always influence the mode of learners' behaviour in the classroom.

To particularize language teaching and learning, it can be said that many linguists, language teaching experts and researchers including Cole (1991), Holliday (1992, 1994), Philipson (1992), Pennycook (1994), Young (1987), Shamim (1996) and LoCastro (1996) now plead for culture sensitive methodology. They argue that pedagogical solutions for a language teaching and learning should be sought within the existing educational structures and cultural contexts so that they can be feasible within the existing socio-economic realities, on the one hand, and can prove culturally appropriate, on the other hand. They oppose any idea of importing a method from one society to another society since a method always contains the cultural features of the society of its origin and contradicts the culture of the society where it is applied. According to Ellis (1996), there are different meaning systems across cultures which inhibit the transferability of particular teaching-learning practices from one society to another. If an imported method is to work in a local context, we need to bring about a radical change in the cultural behaviours and profiles of learners. But it is quite impossible to bring about such a change overnight. Considering this impossibility, the experts suggest either a formulation of the principles of a language teaching method on the basis of the local cultural features, or an adaptation to an imported method with these features. Samson (1984) categorically says that teaching methods cannot be imported with the notion that they are universally appropriate. He argues that teaching methods, like scientific theories, are not value-free, but value-laden; and so, if they are imported from one country to another country, there may be a mismatch between the values inherent in those methods and the values prevalent in the culture of the importer country.

\section{The Cultural Features of the Contexts of Bangladesh}

What the above discussion signifies is the necessity of a good match between the mode of language teaching-learning activities in the classroom and the cultural orientation of the participants of these activities. Obviously, to ensure the effective teaching and learning of English as a foreign language in Bangladesh, what is required is to determine the mode of classroom instruction on the basis of the cultural profiles of the learners and the teachers, specially the learners, of the country. If the instructional system is not harmonious with the cultural traits of the learners, they will not be able, as it has been discussed above, to behave competently in the classroom and, therefore, will not be able to learn effectively.

The cultural profiles of the learners of Bangladesh can be explored through a proper analysis of the cultural features of the family as well as of the wider society where they live and are socialized into the cultural members of their society. To analyze the family culture in Bangladesh, it is found that the society of Bangladesh is a hierarchical one where family is a very important institute. A family in Bangladeshi society plays a very vital role to initiate children to the established patterns of the norms and behaviours of the society. In the family elders and parents command high respect and obedience from children, and take decisions for them on all important 
matters of their lives including choice of education, choice of career, selection of life partners and so on. The children are wanted only to show their obedience to these decisions. Any disobedience or disrespect to these decisions on the part of children is very negatively evaluated in family. As a result, children do not grow up by sharing ideas or views with their parents or elders on any matter concerning either themselves or any other member of their family. They are, in other words, discouraged from giving any independent opinions or making any arguments against the views and opinions of their parents and elders, which always makes them depended upon their parents and elders for a decision about any matter of their lives.

As in the family, in the wider society too, children are not considered equal partners in any discussion or conversation with those who are senior in age. It is thought that those who are superior to them either in age or in experience or in power have the authority to pass their opinions about something, and those who are inferior in age or in experience or in power are morally bound to respect those opinions. The cultural situation of the society of Bangladesh can be compared with that of the society of Pakistan. Both Bangladesh and Pakistan belong to South Asia and do have similar kinds of cultural features. Regarding the cultural features of the society in Pakistan, Shamim (1996) says,

The advice of superiors is interpreted as an order which is binding on those lower in rank or authority. It is believed that people younger in age, and consequently lacking in experience, need to be constantly guided and advised by those who know 'better', i.e. elders, superiors, etc. The development of an independent mind, especially in the young, is positively discouraged and interpreted as 'offensive' behaviour and a threat to parental and other forms of authority.

Like Pakistan, in Bangladesh as well, it is believed that the younger people are lacking in experience and, therefore, need to be constantly guided and advised by the older or the senior. Asking questions to the seniors, or showing too much curiosity about any matter of the seniors is rated as impoliteness on the part of children. But, paying no respect to the opinions of their fellow mates is not treated as transgression of any good conduct.

As to the educational culture in Bangladesh, it is noticed that the educational culture in the country is the microcosm of the common culture prevailing in the wider society of the country and is also little different from those of the other countries in Asia. Depicting the educational culture of Bangladesh, Islam (2000) says that teachers here are like guardians and "asking too many questions to and entering into a debate or argument with the teachers is a sign of disrespect and teachers hardly appreciate it." In Bangladesh "knowledge is seen as a monolithic entity, a finite, inflexible 'object', to be accepted whole and to be memorized and regurgitated" (Rahman 1999). That is, knowledge is regarded here as something that needs to be transmitted to learners by teachers, and to be received and memorized by learners. It is not something that needs to be created through logical analysis as is done in the Western culture. Books are regarded here as an embodiment of knowledge, truth and sacredness that cannot be questioned. Learners believe in the ultimate authority of textbooks as the syllabuses on which they are based are content-driven. Referring to the authority which textbooks enjoy in Bangladesh, Rahman (1999) says, "As in many educational cultures, textbooks carry a unique authority and are understood as the legitimate version of the society's sound knowledge." Learning is thought to be difficult, text-based, content-focused and exam-oriented that should be pursued in a systematic and disciplined way. "Intensive reading" here means, as is found in Chinese culture as mentioned by Maley (1983), pursuing a text word by word, phrase by phrase, explaining points of vocabulary, syntax, style and context throughout the process. Learners are expected to be hardworking and respectful to their teachers, and teachers, in their turn, are expected to be strict, formal, omniscient and caring. Like Japanese students as mentioned by McHugh (1989), the students of Bangladesh too expect that their teachers will teach them seriously and will behave with them in a dignified manner in the classroom, avoiding making any kind of informal and casual gestures or putting on casual dresses.

\section{The Culturally Appropriate Mode of Instruction for ELT in Bangladesh}

Based on the above picture of the cultural realities in Bangladesh, it can be said that the cultural pattern through which the learners of the country go in their socialization in the educational institutes, in the family and in the wider community outside the family injects into their characters the values of obedience, allegiance, acceptance and dependence. That is, the very socialization process in the culture of Bangladesh makes them dependent on their seniors and superiors, instead of making them self-dependent, self-reliant and confident. Again, the same cultural pattern of the country makes them disrespectful to their fellow mates or peers. These cultural traits of the learners of Bangladesh signify that the mode of classroom instruction that would be appropriate for them must be teacher-dominated or teacher-fronted. That is, learners will learn better if they can learn under the control, guidance and directions of teachers. The culture sensitiveness of this proposition can be verified by investigating 
the beliefs and expectations that both the teachers and the learners of the country hold about their roles in the classrooms. It can be mentioned that the beliefs and expectations of the teachers and learners of Bangladesh are deeply rooted in the cultural phenomena of the country. Shahidullah $(1997,124,185$, \& 200), in an empirical study on the teaching-learning culture of Bangladesh, has found that the learners of Bangladesh want to learn under the guidance of their teachers. Not only that, even the teachers of the country believe that learners learn best when they learn under their control. The same kinds of results are found by Wasiuzzaman (2012) in his study done on 20 teachers and 30 students of some secondary schools and colleges of the country to know their beliefs about what should be their roles in the classroom in learning English. Wasiuzzaman finds that teachers here refuse to accept the view that language learning is students' responsibility. They think that it is mainly teachers' responsibility to ensure students' learning, because "if the students are left on their own, they will hardly understand what is useful and what is useless for them." Students, on their part, believe that teachers are "experienced people" and "a rich source of knowledge"; therefore, they (teachers) should "enlighten" them (students) with their knowledge. Wasiuzzaman mentions that regarding the question whether they should take the responsibilities for their learning on their own shoulders, most of the students say, "We cannot help depending on them whether we like it or not; if students are given all the main responsibilities for ensuring learning, its results will not be good." Mentioning the expectations of Bangladeshi students, Islam (2000) says, "In most cases students in Bangladesh expect that their teacher will explain everything without being asked. They also expect that all initiatives in matters of teaching and learning should come from the teacher's side."

Therefore, in the cultural model of instruction in Bangladesh teachers should remain at the centre of all classroom activities, determining the pace, directions and process of learning. They should take the responsibility of identifying learners' needs and choosing the course contents accordingly. In addition to these, they should also select the methods and techniques of learning that will be suitable for learners, monitor the progress of learners, evaluate their achievement and keep the learning activities on right tracks. To impart language skills to learners, they should involve them (learners) in the practice of using English as much as possible through different types of tasks and activities suitable for the teacher-fronted classrooms. That is, teachers should also take the responsibility of engaging students in various kinds of activities, along with delivering lectures. The tasks and activities that will be suitable for this mode of classroom instruction are varied kinds of individual tasks and activities, teacher-student interactions, the whole class interactions and so on. Relevantly, it should be mentioned that only delivering lecture or transmitting knowledge about English language as is done in the case of teaching many other subjects like history, political science, sociology, etc., in the educational culture of Bangladesh will not suffice for the purpose of English language teaching and learning. When language is a skill-based subject, these are content-based. Therefore, there should be an attempt on the part of the teachers, and the syllabus and materials designers to involve the learners in the practice of using English through classroom interactions and other suitable tasks and activities within the purview of teacher-centredness so that they can acquire required skills in it.

The cultural traits of the learners of Bangladesh do not match with the progressive modes of language teaching and learning that have originated from English speaking countries. The progressive modes like "learner autonomy", "individualized instruction" or "learner-centred language teaching", and so on, suggest some specific pedagogical principles, keeping harmony with the cultural features of the Western societies. For example, "learner autonomy" recommends that learners should learn a language autonomously, taking the responsibility of their own learning. According to Holec (1977, 9), "autonomy" means the ability to take charge of one's own learning. Stanchina (1975), to point out the major features of learner autonomy, says that in this concept the learner determines his mode of learning, the materials he will use and the pace of the intake of materials. Similarly, the concept of 'individualized instruction' also demands taking a lot of responsibilities on the part of individual learner for his/her own learning. The concept of "learner-centred language teaching" that has emerged with the advent of the Communicative Language Teaching (Nunan 1988, 24) also requires learners to play the central role in the classroom. In this concept, they are expected to select materials, to choose their styles and techniques of learning, to monitor their own activities, to learn through mutual co-operation with their fellow learners, to make self-correction, to promote peer-correction, etc. In short, learners, according to this concept, are required to be at the centre of all the classroom activities, deciding and controlling what they will learn and how they will learn. In this regard, Brindley (1984, 15 cited in Nunan 1988, 23) says,

...instructional programmes should be centered around learners' needs and that learners themselves should exercise their own responsibility in the choice of learning objectives, content and methods as well as in determining the means used to assess their performance.

All these classroom practices of self-monitoring, self-correction, peer-correction, taking responsibility for what and how to learn, co-operative learning, group work, pair work and so on of the progressive modes of language 
teaching and learning do not appear to be culturally appropriate for the learners of Bangladesh. All these activities demand high confidence, boldness, individuality, independence of mind, respect to fellow learners and so on, but the learners here significantly lack these traits in their characters owing to their cultural factors. Therefore, if they are involved in doing such activities, they will feel uncomfortable and, hence, will not learn effectively, especially at the lower level of the main stream education of Bangladesh where they are not mature enough in age. According to Rahman (1999), "the culture of learner-centred, discovery-oriented tasks in the progressivist tradition, much favoured in communicative ELT circles today, apparently does not appear to suit the educational and socio-psychological ethos of learning in Bangladesh today." Actually, in the context of the current educational ideology of Bangladesh exhibiting a classical humanistic orientation, the ideology of progressivism is bound to bring about mismatches. In his empirical study on 95 students of the department of English of Rajshahi University, Islam (2000) finds that they do not like the ideology of learner autonomy because they are not willing to take the responsibilities involved in this ideology.

To cite the present scenario of ELT in Bangladesh, it should be mentioned that the Communicative Approach or the CLT that is now being followed, after its introduction in the late 90s of the last century into the country, for teaching English as a foreign language does not match with the teacher-centered classroom. Consequently, the task of the teaching of English is not being properly done in the country, which leads to the poor outcome of English education. The classroom activities like the pair work, group work, role-play that the CLT suggests and the learner autonomy that it recommends are rarely seen being practised here. Though the textbooks that have been newly written for each class at the primary, secondary and higher secondary levels of education in accordance with the principles of the CLT after its introduction into the country contain a lot of these kinds of tasks and activities, neither the teachers nor the students are found showing any eagerness for them. "But, the fact is that ELT teachers bypass these activities and attribute this avoidance to various social, cultural and logistic constraints" (Chowdhury 2012, 6). Citing Afroze \& Rahman (2008) and Rahman (2011), Haider \& Chowdhury (2012) in an empirical study "to identify ways of adjusting the features of CLT to Bangladeshi classroom realities" state that after more than a decade of introducing the CLT in Bangladesh, students of secondary schools are still struggling to achieve desired level of proficiency in English. For the failure to achieve the desired goal in ELT, Haider and Chowdhury hold the non-implementation of the principles of the CLT responsible. They comment, "... the implementation of the methodological underpinning of the communicative approach is being impeded by many constraints that exist in the present teaching-learning context." Interestingly, by "constraints" they have indicated only those contextual problems that are overt, such as, lack of teachers' training, lack of teachers' guide, shortage of supplementary and bridging materials, faulty examination system, etc., but they have mentioned nothing about other contextual problems that are cultural and hidden. Though in their study they have found that 'the learners feel shy and reluctant to speak out' and that they ( the learners) believe that "their teacher is responsible for doing everything", they have not regarded their "feelings" and "beliefs" as "constraints" in their study. That is, they have ignored the fundamental problems which are deeply rooted in the culture of Bangladesh in case of implementing the principles of the CLT. Actually, how far the CLT is adoptable in a context should be determined/considered first of all in terms of the cultural profiles of the teachers and learners of that context because when in adopting the principles of CLT other problems can be solved with the help of money, men and materials, the culture-related problems are not solvable unless culture itself is changed.

Obviously, for ELT in Bangladesh the wholesale application of the CLT will not be appropriate. Instead, only those very principles or elements of it that are useful for acquiring language skills as well as adaptable to the teacher-fronted classroom should be adopted. That is, for ELT in the country a new method has to be formulated, taking the necessary elements from the progressive modes of language teaching, on the one hand, and also recognizing/accommodating the socio-cultural realities of Bangladesh, on the other hand. After analyzing various aspects of the social and educational culture of Bangladesh, Rahman (1999) remarks that for ELT innovation in Bangladesh a "synthesis" model embracing different models as deemed appropriate can be formulated. According to her, the model of classroom instruction that would be appropriate for ELT in Bangladesh will be the blending of both the global or progressive elements and the local or contextual elements. Considering the cultural realities as well as the necessity of imparting language skills to the learners so that they can meet their global needs, Sahahidullah (2000) suggests that "a teacher-centred, but task-based, activity-oriented and skills-focused ELT pedagogy will prove appropriate for Bangladesh.” In another study to explore an appropriate methodology for ELT in Bangladesh, he (1999) states that under teachers' control the individual tasks, not the tasks in groups and pairs, will prove more useful in Bangladesh. Besides, interactions with texts, free discussion in whole class sessions, seminar and tutorial discussion, etc., can also be utilized more meaningfully and effectively in the country. 


\section{Conclusion}

The claim that there is a close relationship between culture and learning is now well established. Besides, the failure of the behavioural and cognitive psychology to provide explanations for some issues of learning has strengthened the argument in favour of this close relationship. Based on this relationship it is now very strongly argued that learners can learn in a meaningful way if they find a harmony between the classroom teaching-learning practices and the cultural features of the society of which they are the members. Therefore, it is very important to know the cultural profiles of the learners and the teachers which they acquire through their socialization in the culture of the wider society, and to determine the mode of classroom instruction accordingly. An analysis of the cultural profiles of the learners and the teachers of Bangladesh signifies that teacher-centred classroom would be culturally appropriate for ELT in the country. Learner-centred classroom or the progressive modes of language teaching and learning will make a mismatch with the cultural orientation of the learners and the teachers, and will create obstacles for them to behave competently in the classroom. In the classroom the teachers should be the central figures, controlling and monitoring all the activities about learning so that the learners can learn under the guidance and supervision of their teachers comfortably and effectively. Obviously, the CLT that fosters leaner-centredness and that is now being followed for teaching English as a foreign language in Bangladesh fails to yield the desired results owing to the mismatch between the principles of the CLT and the cultural features of the learners and the teachers of the country. Under such circumstances, a new method needs to be developed, taking the suitable elements from the progressive modes or the CLT and placing the teachers at the central point in the classroom.

\section{References}

Afroze, R. K., \& Rahman, A. M. M. H. (2008). English teachers' classroom practices in rural secondary schools: An exploration of the effect of BRAC training. Bangladesh Education Journal, 7, 7-16.

Brindley, G. (1984). Needs Analysis and Objective Setting in the Adult Migrant Education Program. Sidney: NSW Adult Migrant Education Service.

Chowdhury, Md. K. B. (2012). Communicative Language Teaching Approach at Higher Secondary Level in Bangladesh-Teachers' Perceptions and Classroom Practice. Language in India, 12. Retrieved from http://www.languageinindia.com/feb2012/chaudhurydissertationfinal.pdf

Cole, M. (1991). A Cultural Theory of Development: What Does It Imply about the Application of Scientific Research? Learning and Instruction, 1, 187-200. http://dx.doi.org/10.1016/0959-4752(91)90002-P

Cole, M. (1996). Cultural Psychology: A Once and Future Discipline. Cambridge, MA: Belknap Press.

Donaldson, M. (1978). Children's minds. London: Fontana Press.

Ellis, G. (1996). How Culturally Appropriate is the Communicative Approach? ELT Journal, 50(3), 213-218. http://dx.doi.org/10.1093/elt/50.3.213

Gladwin, T. (1970). East is a big bird. Cambridge: Harvard University Press.

Haider, Md. Z., \& Chowdhury, T. A. (2012). Repositioning of CLT from Curriculum to Classroom : A Review of the English Language Instructions at Bangladeshi Secondary Schools. International Journal of English Linguistics, 2(4). http://dx.doi.org/10.5539/ijel.v2n4p12

Holec, H. (1981). Autonomy and Foreign Language Learning. Oxford: Pergamon.

Holliday, A. (1992). Tissue Rejection and Informal Orders in ELT, Projects: Collecting the Right Information. Applied Linguistics, 15, 403-424. http://dx.doi.org/10.1093/applin/13.4.403

Holliday, A. (1994). Student Culture and English Language Education: An International Perspective. Language Culture and Curriculum, 7(2), 125-143. http://dx.doi.org/10.1080/07908319409525172

Islam, J. (2000). The Concept of Learners Autonomy and Its Feasibility in Bangladesh. In ELT 2000 : Directions and Orientations (Proceedings of a Seminar held at the Department of English, Rajshahi University, January 30-31, 2000, pp. 29-36). Rajshahi: Rajshahi University.

Keil, F. C. (1989). Concepts, Kinds, and Cognitive Development. Cambridge: MIT Press.

Lantolf, J. P. (1999). Second Culture Acquisition: Cognitive Consideration. In E. Hinkel (Ed.), Culture in Second language Teaching and Learning (pp. 28-46). Cambridge: Cambridge University Press.

Lantolf, J. P. (2000). Introducing Sociocultural Theory. In J. P. Lantolf (Ed.), Sociocultural Theory and Second Language Learning (pp. 1-26). Hong Kong: Oxford University Press. 
LoCastro, V. (1996). English Language Education in Japan. In H. Coleman (Ed.), Society and the Language Classroom (pp. 40-58). Cambridge: Cambridge University Press.

Maley, A. (1983). Xanadu. A Miracle of Rare Device: The Teaching of English in China. Language Learning and Communication, 2(1), 97-103.

McHugh, C. (1989). Socio-Cultural Factors Differentiating EFL and FSL Environments. In V. Bickley (Ed.), Language Teaching and Learning Styles within and across Cultures (pp. 293-309). Hong Kong: Institute of Language Education.

Nunan, D. (1988). The Learner-Centred Curriculum. Cambridge: Cambridge University Press.

Pennycook, A. (1994). Cultural Politics of English as an International Language. London: Longman.

Philipson, R. (1992). Linguistic Imperialism. Oxford: Oxford University Press.

Pinxten, R. (1991). Geometry Education and Culture. Learning and Instruction, 1, 217-227. http://dx.doi.org/10.1016/0959-4752(91)90004-R

Rahman, A. (1999). ELT Innovation and Cultural Change: A Bangladeshi Perspective. In T. Hunter (Ed.), Collected Papers of International Conference on National and Regional Issues in English Language Teaching: International Perspectives (pp. 235-254), held at the British Council, Dhaka from January 31 to February 2, 1999.

Saljo, R. (1991). Introduction: Culture and Learning. Learning and Introduction, 1, 179-185. http://dx.doi.org/10.1016/0959-4752(91)90001-O

Sampson, G. P. (1984). The Educational Versus the Scientific Basses of the Communicative Approach. Paper Presented at Nineteenth Regional Seminar Arranged by SEAMEO Regional Language Centre. Singapore : on 24th April, 1984.

Scribner, S., \& Cole, M. (1981). The Psychology of Literacy. Cambridge, MA: Cambridge University Press.

Shahidullah, M. (1997). Teaching-Learning Culture in Bangladesh and Recent ELT Theories: Confrontation and Contradiction (Unpublished doctoral Dissertation). University of Pune, India.

Shahidullah, M. (1999). Towards an Appropriate Methodology for ELT in Bangladesh. In T. Hunter (Ed.), Collected Papers of International Conference on National and Regional Issues in English Language Teaching: International Perspectives (pp. 45-68), held at the British Council, Dhaka from January 31 to February 2, 1999.

Shahidullah. M. (2000). Norms in ELT: Shifts in Focus and Implications for Bangladesh. In ELT 2000: Directions and Orientations (Proceedings of a Seminar held at the Department of English, Rajshahi University, January 30-31, 2000, pp. 9-28). Rajshahi: Rajshahi University

Shamim, F. (1996). Learner Resistance to Innovation in Classroom Methodology. In Hywel Coleman (Ed.), Society and the Language Classroom (pp. 105-121). Cambridge: Cambridge University Press.

Shore, B. (1996). Culture in Mind: Cognition, Culture and the Problem of Meaning. Oxford: Oxford University Press.

Stanchina, C. (1975). The logic of Autonomy as a Strategy for Adult learners. Paper presented at the AILA Conference, University of Nancy, CRAPEL. Mimeo.

Vosniadou, S. (1991). Are We Ready for a Psychology of Learning and Culture? Learning and Instruction, 1, 283-287. http://dx.doi.org/10.1016/0959-4752(91)90009-W

Vygotsky, L. S. (1978). Mind in Society. Cambridge, MA: Harvard University Press.

Wasiuzzaman, M. (2012). Teachers' and Students' Roles in English Language Classrooms in Bangladesh: Some Beliefs. Praxis, Journal of the Department of English, 4. Rajshahi: Rajshahi University.

Young, R. (1987). The Cultural Context of TESOL: A Review of Research into Chinese Classrooms. RELC Journal, 18(2), 15-30. http://dx.doi.org/10.1177/003368828701800202 